\title{
Inscription of narrow bandwidth Bragg gratings in polymer optical fibers
}

\author{
Carlos A. F. Marques ${ }^{* a}$, Lúcia Bilro ${ }^{a}$, David J. Webb ${ }^{b}$, Rogério N. Nogueira ${ }^{a}$ \\ ${ }^{a}$ Instituto de Telecomunicações, Pólo de Aveiro, 3810-193 Aveiro, Portugal; \\ ${ }^{\mathrm{b}}$ Aston Institute of Photonic Technologies, Aston University, Birmingham, B4 7ET, UK
}

\begin{abstract}
We report on the production and characterization of narrow bandwidth fiber Bragg gratings (FBGs) in two spectral regions using polymer optical fibers (POFs). Narrow bandwidth FBGs are increasingly important for POF transmission systems, WDM technology and sensing applications. Long FBGs with resonance wavelength around $850 \mathrm{~nm}$ and $1550 \mathrm{~nm}$ were fabricated in several types of polymer optical fibers. The $3 \mathrm{~dB}$ FBG bandwidth varies from $0.22 \mathrm{~nm}$ down to $0.045 \mathrm{~nm}$ considering a Bragg grating length of $10 \mathrm{~mm}$ and $25 \mathrm{~mm}$, respectively.
\end{abstract}

Keywords: Polymer optical fibers, fiber Bragg gratins, narrow bandwidth, exposure time, spectral properties.

\section{INTRODUCTION}

The choice of the fiber material for optical fiber has so far been silica, because of its low loss and resistance to high temperatures. However, polymer optical fibers (POFs) are starting to be considered a viable alternative to silica fibers (SF) in applications such as short distance transmissions ${ }^{1,2}$, sensing ${ }^{3,4}$, terahertz waveguides and filters ${ }^{5}$, in-building networks ${ }^{6,7}$, and radio over fiber systems ${ }^{8}$. One of the major drawbacks pointed to POFs is the greater attenuation coefficient as compared to SF, a fact that limits their applications. POFs made of standard poly(methyl methacrylate) $\left(\mathrm{PMMA}^{4,9}\right.$ and TOPAS $^{3}$ have very high losses of more than $100 \mathrm{~dB} / \mathrm{m}$ at $1550 \mathrm{~nm}$. This makes it hard to work with POFs at the C-Band wavelength region, unless very short sections of fiber are used. However, recent studies show that the use of perfluorinated polymers as core materials can significantly reduce loss ${ }^{10,11}$. A significant decrease in the material loss can be also achieved by working at lower wavelengths. In particular, the $0.06 \mathrm{~dB} / \mathrm{m}$ and $0.2 \mathrm{~dB} / \mathrm{m}^{12,13}$ target is possible at the wavelength range $520-850 \mathrm{~nm}$ at which CMOS (complementary metal-oxide-semiconductor) technology is available ${ }^{12}$. For this reason, currently there is a strong push in the optical communication and sensing community to develop polymer devices in the near-infrared (NIR) window.

POF fiber Bragg gratings (POF FBGs) are an attractive technology due the easy integration in optical components and to be cost effective for data communication ${ }^{1,2,6-8,11-14}$, lasers ${ }^{15}$ and sensor applications $s^{3,4,9}$. POF FBGs have been reported in step index POFs (SI-POF) ${ }^{9}$ and microstructured POFs (mPOFs) ${ }^{3,9}$ including both singlemode (SM FBGs) and multimode fibers (MM FBGs). Most of the POF FBGs reported to date had a resonance wavelength around $1550 \mathrm{~nm}$. Recently a $10 \mathrm{~mm}$ narrow bandwidth FBG at $850 \mathrm{~nm}$ was reported for two types of few-moded POFs, mPOF and SI-POF ${ }^{9}$. Authors reported bandwidths of $0.29 \mathrm{~nm}$ and $0.17 \mathrm{~nm}$ using the expanded beam inscription method 9 .

Here we present the inscription of narrow bandwidth $830 \mathrm{~nm}$ and $1550 \mathrm{~nm}$ FBGs in different types of POFs using the phase-mask technique with shorter exposure time and better spectral properties than what it was reported in the literature. A $25 \mathrm{~mm}$ long POF FBG is also reported.

\section{EXPERIMENTAL SET-UP}

The gratings were inscribed using a $30 \mathrm{~mW} \mathrm{CW} \mathrm{HeCd} \mathrm{laser} \mathrm{operating} \mathrm{at} 325 \mathrm{~nm}$ (IK3301R-G, Kimmon). The experiment setup is shown in Figure 1. The fiber was supported by v-grooves on both sides with a gap between to avoid reflection and it was taped down to ensure that the fiber did not sag. A cylindrical lens $(\mathrm{f}=10 \mathrm{~cm})$ was used to focus vertically downward the laser light on the optical fiber in order to increase the power density onto the fiber's core. The pattern imprinted into the fiber is determined by the phase mask (Ibsen Photonics), placed just above the fiber, whose uniform periods of $557.2 \mathrm{~nm}$ and $1042.7 \mathrm{~nm}$ are optimized for POF FBGs in the $830 \mathrm{~nm}$ and $1550 \mathrm{~nm}$ spectral range. With the aim to inscribe the long FBGs proposed in this work $(10 \mathrm{~mm}$ and $25 \mathrm{~mm})$, the laser was scanned along the phase mask. The scanning of the phase mask was made by a motorized linear stage with a specific speed, $v(\mathrm{~mm} / \mathrm{s})$.

Fifth European Workshop on Optical Fibre Sensors, edited by Leszek R. Jaroszewicz, Proc. of SPIE Vol. 8794, $879423 \cdot$ C 2013 SPIE · CCC code: $0277-786 X / 13 / \$ 18 \cdot$ doi: $10.1117 / 12.2026089$ 


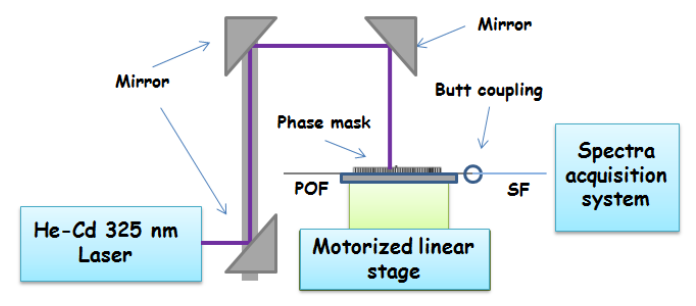

Figure 1. Schematic diagram of FBG inscription system.

At $1550 \mathrm{~nm}$, the reflected spectra were monitored by an interrogation system (Micron Optics 125-500) with wavelength accuracy of $1 \mathrm{pm}$. A temporary connection was made using a FC/APC contact connector and a single mode fibre optic cable. A small amount of index matching gel was used in order to reduce Fresnel reflections, lowering the background noise. The growth of the $830 \mathrm{~nm}$ FBGs was monitored in reflection with a spectral resolution of $0.01 \mathrm{~nm}$ using an 850 $\mathrm{nm}$ 1x2 silica fiber coupler (SM or MM accordingly), a broadband light source HL-2000 (Ocean optics) and a spectrometer USB2000+VIS-NIR (Ocean optics).

\section{EXPERIMENTAL RESULTS AND DISCUSSION}

Gratings fabrication conditions and POF specifications are described in Table 1 for the 10-mm-long FBGs inscription. With respect to the MORPOF 02, it is single moded at $1300 \mathrm{~nm}$ (or greater). This fiber has numerical aperture (NA) of 0.27 at $1100 \mathrm{~nm}$ and, consequently, the normalized frequency $V$ is 3.98 at $850 \mathrm{~nm}$. This value indicates that the fiber will support 6 modes at $850 \mathrm{~nm}$. We further observed that a shorter exposure time (Table 1) was needed in relation to the presented in the literature, ${ }^{9,17}$ and we also achieve a good amplitude response.

Table 1. POFs parameters and FBGs fabrication conditions.

\begin{tabular}{|c|c|c|c|c|}
\hline \multicolumn{3}{|l|}{ POF Specification } & \multirow{2}{*}{$\begin{array}{l}\text { Exposure } \\
\text { time (min) } \\
\end{array}$} & \multirow{2}{*}{$\begin{array}{l}\text { Microscope image } \\
\text { of the end facet }\end{array}$} \\
\hline Core diameter $(\mu \mathrm{m})$ & Outer diameter $(\mu \mathrm{m})$ & Rings of holes & & \\
\hline \multicolumn{5}{|c|}{ Few mode mPOF (Kiriama) } \\
\hline 15 & 150 & 4 & 45 & 6. \\
\hline \multicolumn{5}{|c|}{ SM fiber: ${ }^{a} M O R P O F 02$ (Paradigm Optics) and ${ }^{b} m P O F$ (Kiriama) } \\
\hline a 3.13 & 115 & $\mathrm{n} / \mathrm{a}$ & 20 & \\
\hline${ }^{\mathrm{b}} 6$ & 125 & 6 & 45 & \\
\hline \multicolumn{5}{|c|}{ MM fiber (Kiriama): ${ }^{c} m P O F$ G3 and ${ }^{d} m P O F$} \\
\hline c 34 & 250 & 1 & 83 & \\
\hline${ }^{\mathrm{d}} 50$ & 150 & 3 & 83 & \\
\hline
\end{tabular}

The PMMA few mode mPOF (Kiriama) has 4 rings of holes separated with a pitch of $9.61 \mu \mathrm{m}$ and a hole size of $4.2 \mu \mathrm{m}$. The relative hole size of 0.44 means that the $\mathrm{mPOF}$ is few-mode at $850 \mathrm{~nm}^{16}$. Simulation results showed that this mPOF presented three modes at $850 \mathrm{~nm}$ and is singlemoded at $1550 \mathrm{~nm}$. These modes and their respective polarizations are shown in Figure 2 (a-c). Figure 2e) depicts a FBG with peak power $15 \mathrm{~dB}$ above noise background and a $3 \mathrm{~dB}$ bandwidth of $0.16 \mathrm{~nm}$ at the $1550 \mathrm{~nm}$ wavelength range.
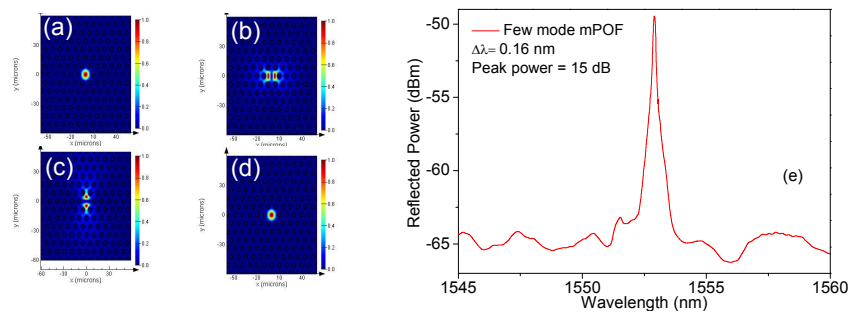

Figure 2. (a-c) Simulated spectral modes of the $\mathrm{mPOF}$ for $850 \mathrm{~nm}$ presenting three modes and their respective polarizations. (d) The fiber presents a single mode at $1550 \mathrm{~nm}$. (e) Reflection spectrum of a few mode mPOF FBG. 
Figures $3 \mathrm{a}$ ) and b) show the amplitude response and $3 \mathrm{~dB}$ bandwidth for the SM POF (MORPOF02) and mPOF achieving 21 and $15 \mathrm{~dB}$ of peak power and $3 \mathrm{~dB}$ bandwidths of 0.11 and $0.22 \mathrm{~nm}$, respectively. The exposure time necessary to write a FBG in an $\mathrm{MPOF}$ is longer than in a solid POF despite the similar diameter and leads to relatively weak gratings. This is because the holes around the core of the mPOF scatter a significant part of the laser power during the writing process ${ }^{18}$. Fig. 3 (c) shows the reflection spectrum of the SM mPOF FBG at $850 \mathrm{~nm}$ with $3 \mathrm{~dB}$ bandwidth of $0.19 \mathrm{~nm}$. The noise level is $16 \mathrm{~dB}$ lower than the peak power. For SM POF (MORPOF02) FBG at $850 \mathrm{~nm}$ we achieve a $3 \mathrm{~dB}$ bandwidth of $0.095 \mathrm{~nm}$, which is less than the previously published results ${ }^{9}$. At the $1550 \mathrm{~nm}$ wavelength range, both multimode mPOF FBGs display similar peak powers for the same exposure time however the $3 \mathrm{~dB}$ bandwidth is $0.15 \mathrm{~nm}$ for the MM mPOF G3 (Fig. 3 (d)) and $0.08 \mathrm{~nm}$ for the MM mPOF (Figure 3 (e)). This difference may be due to the distinct geometry of air holes and fiber diameter (core and outer). The MM mPOF FBG is shown in Figure 3f) at the $850 \mathrm{~nm}$ spectral window and it exhibits a peak power and a $3 \mathrm{~dB}$ bandwidth of $15 \mathrm{~dB}$ and $0.11 \mathrm{~nm}$, respectively. Comparing the aforementioned results, the highest $3 \mathrm{~dB}$ bandwidth was obtained for the single mode mPOF which can be explained by the highest number of rings of holes that this fiber presents. The lower than expected $3 \mathrm{~dB}$ bandwidth obtained for MM mPOF when compared to SM mPOF can be due to the excitation of only one mode because a single mode fiber optic cable was used to link the grating to the interrogating system.
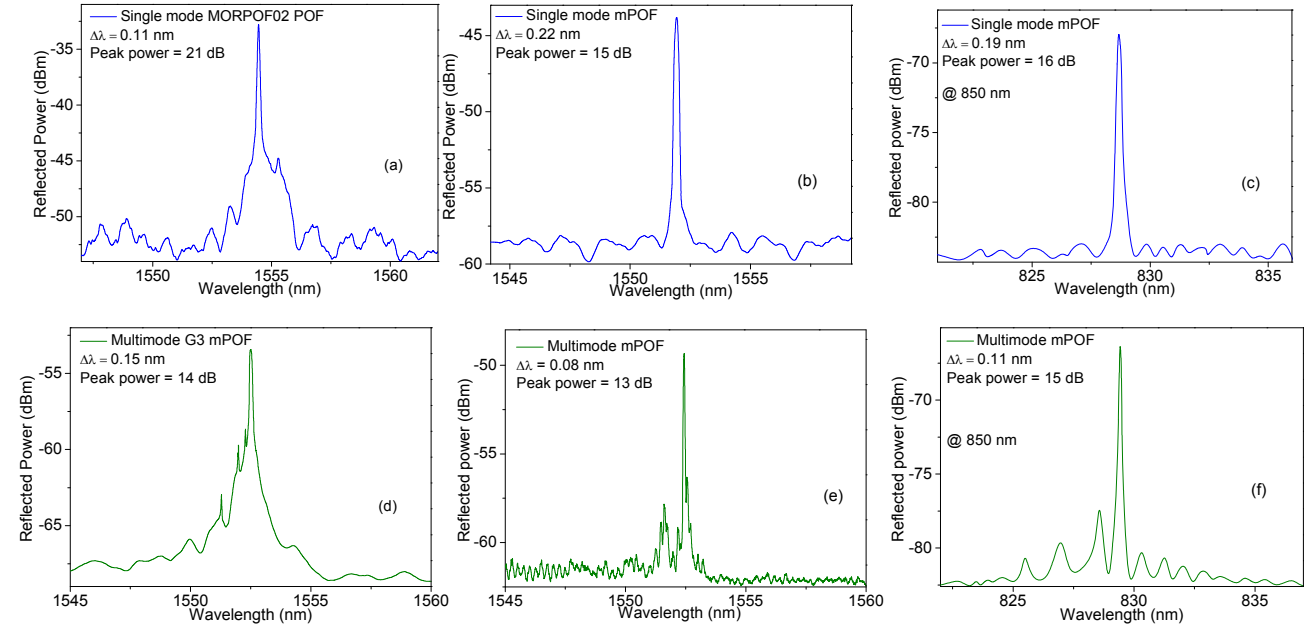

Figure 3. Reflection spectra of FBGs written in: (a) SM MORPOF02, (b-c) SM mPOF, (d) MM G3 mPOF and (e-f) MM mPOF.

Figure 4 shows the reflection spectrum of the grating with $25 \mathrm{~mm}$ length inscribed in the few mode mPOF at the $1550 \mathrm{~nm}$ window. This spectrum was recorded before saturation after a writing time of $105 \mathrm{~min}$. This FBG presents a peak power $17 \mathrm{~dB}$ above the background and the narrowest $3 \mathrm{~dB}$ bandwidth was obtained $(0.045 \mathrm{~nm})$.

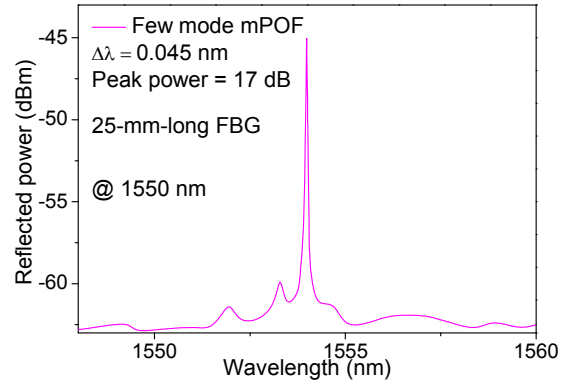

Figure 4. Reflection spectrum of a few mode mPOF FBG with length of $25 \mathrm{~mm}$ and a center wavelength of $1553.04 \mathrm{~nm}$.

These results show a significant improvement in amplitude response, $3 \mathrm{~dB}$ bandwidth and exposure times when compared with those reported in the literature. An explanation for this fact is a better use of laser power due to the small optical path until the fiber and the employment of the motorized linear stage to do the scanning of phase mask (instead of expanding the laser beam method). We note that the $3 \mathrm{~dB}$ bandwidth response can be different from fiber to fiber depending on the material ${ }^{9}$. Thus, even though all fibers used in this work are made of PMMA, the material can vary 
from manufacturer to manufacturer and the drawing conditions may have been different, meaning that our mPOF and POF FBGs should not have a priori the same response. Since our setup has been the same for the different inscriptions, this hints that, in fact, the different experimental setups play also an important role.

\section{CONCLUSION}

In summary, narrow bandwidth FBGs in different types of POFs and also different spectral windows were reported. The $3 \mathrm{~dB}$ bandwidths ranged from 0.22 down to $0.045 \mathrm{~nm}$ considering grating lengths of 10 and $25 \mathrm{~mm}$. The low attenuation window at a lower wavelength is definitely a candidate for future POF transmission systems using CMOS technology, in particular when taking into account that the loss can be further reduced by improvement of the fabrication technology. In addition, we believe that the POF FBGs fabricated with particular characteristics (such as narrow $3 \mathrm{~dB}$ bandwidth and amplitude response) can be potentially used as optical devices in POF link systems ${ }^{19}$, overcoming limitations existing at lower wavelength. Further developments will be focused in the inscription of FBGs in the visible spectrum. Other types of gratings such as phase shifted FBGs will be investigated for tunable cavities and notch filters to be used in photonic applications in the VIS-NIR window.

\section{ACKNOWLEDGMENTS}

The authors acknowledge the support from FCT (Portuguese Foundation for Science and Technology) through the projects PTDC/CTM/101538/2008; PTDC/SAU-BEB/100650/2008; PTDC/EEA-TEL/114144/2009 and PTDC/EEATEL/122792/2010. Lúcia Bilro and Carlos Marques gratefully acknowledge the financial support received from the same institution, through fellowships, SFRH/BPD/78205/2011 and SFRH/BD/70661/2010, respectively.

\section{REFERENCES}

[1] M. Atef, R. Swoboda, and H. Zimmermann, "1.25 Gbit/s Over 50 m Step-Index Plastic Optical Fiber Using a Fully Integrated Optical Receiver With an Integrated Equalizer," J. Lightwave Technol. 30, 118-122 (2012).

[2] Y. Shi, C. Okonkwo, D. Visani, E. Tangdiongga, and T. Koonen, "Distribution of Broadband Services Over 1mm Core Diameter Plastic Optical Fiber for Point-to-Multipoint In-Home Networks," J. Lightwave Technol. 31, 874-881 (2013).

[3] W. Yuan, L. Khan, D. Webb, K. Kalli, H. Rasmussen, A. Stefani, and O. Bang, "Humidity insensitive TOPAS polymer fiber Bragg grating sensor," Opt. Express 19, 19731-19739 (2011).

[4] W. Zhang, D. Webb, and G. Peng, "Investigation Into Time Response of Polymer Fiber Bragg Grating Based Humidity Sensors," J. Lightwave Technol. 30, 1090-1096 (2012).

[5] S. Zhou, L. Reekie, H. Chan, Y. Chow, P. Chung, and K. Man Luk, "Characterization and modeling of Bragg gratings written in polymer fiber for use as filters in the THz region," Opt. Express 20, 9564-9571 (2012).

[6] P. Polishuk, "Plastic optical fibers branch out," IEEE Commun. Mag. 44(9), 140-148 (2006)

[7] O. Ziemann, J. Krauser, P. E. Zamzow, W. Daum, POF Handbook-2nd ed. Berlin,Heidelberg: Springer, (2008).

[8] C. Lethien, C. Loyez, and J.-P. Vilcot, "Potentials of radio over multimode fiber systems for the in-buildings coverage of mobile and wireless LAN applications," IEEE Photon. Technol. Lett. 17(12), (2005).

[9] A. Stefani, W. Yuan, C. Markos, and O. Bang, "Narrow bandwidth $850 \mathrm{~nm}$ fiber polymer optical fibers," IEEE Photon. Technol. Lett. 23(10), 660-662 (2011)

[10] Y. Koike, M. Asai, “The future of plastic optical fiber”NPG Asia Mat. 1, 22-28 (2009).

[11] C. Lethien, C. Loyez, J. Vilcot, N. Rolland, and P. Rolland, "Exploit the Bandwidth Capacities of the Perfluorinated Graded Index Polymer Optical Fiber for Multi-Services Distribution," Polymers 3(3), 1006 (2011).

[12] M. Atef, R. Swoboda, H. Zimmermann, "Real-Time 1.25-Gb/s Transmission Over 50-m SI-POF Using a Green Laser Diode" IEEE Photon. Technol. Lett. 24 (15), 1331-1333 (2012).

[13] K. Makino, T. Kado, A. Inoue, and Y. Koike, "Low loss graded index polymer optical fiber with high stability under damp heat conditions," Opt. Express 20, 12893-12898 (2012).

[14] K.-Y. Park, W.-S. Oh, J.-C. Choi, and W.-Y. Choi, "Design of 250-Mb/s Low-Power Fiber Optic Transmitter and Receiver ICs for POF Applications," J. Semicond. Technol. Sci. 11(3), 221-228 (2011).

[15] H. Liu, G. Peng, H. Liu, and P. L. Chu, "Polymer fiber Bragg gratings tuneable laser " in Optical Fiber Communication Conference(Optical Society of America), paper OWM7 (2006).

[16] B. T. Kuhlmey, R. C. McPhedran, and C. Martijn de Sterke, "Modal cutoff in microstructured optical fibers," Opt. Lett. 27, 1684-1686 (2002).

[17] W. Yuan, A. Stefani, O. Bang, "Tunable Polymer Fiber Bragg Grating (FBG) Inscription: Fabrication of Dual-FBG Temperature Compensated Polymer Optical Fiber Strain Sensors," IEEE Photon. Technol. Lett. 24 (5), 401-403 (2012).

[18] G. Marshall, D. Kan, A. Asatryan, L. Botten, and M. Withford, "Transverse coupling to the core of a photonic crystal fiber: the photo-inscription of gratings," Opt. Express 15, 7876-7887 (2007).

[19] H. Lee, S. Lee, and Y. Son, "CWDM based HDMI interconnect incorporating passively aligned POF linked optical subassembly modules," Opt. Express 19, 15380-15387 (2011). 